\title{
ANALYTICAL STUDY ON THE DYNAMIC OF PHYSICAL, FUNCTIONAL AND MOTRICAL DEVELOPMENT TO BEGINNER PRACTITIONERS OF KARATE SHOTOKAN, CADETS AND JUNIORS
}

\author{
$\begin{array}{lll}\text { M. COJOCARU } & 1 & \text { C. MEREUȚA } \\ & \text { D.A. IORDAN }\end{array}$
}

\begin{abstract}
The purpose of this research is centered on the need to know the physical and motor development of cadets and juniors, shotokan karate practitioners, in order to promote the more efficient organization of sports training lessons. In this process we started from the following hypotheses: the pace of physical development of the cadets and juniors is different from one year to another, the pace of motor development of the cadets and juniors is different from one year to another, the ability to adapt to effort of beginner practitioners of Karate Shotokan, cadets and juniors, is constantly improving and differs from one year of study to another. The application of the tests, the investigation and the rigorous interpretation of the results argue the hypotheses and validate the objectivity and correctness of the experimental action.
\end{abstract}

Key words: cadets, development, juniors, karate, shotokan.

\section{Introduction}

The movement that man performs every moment is one of the basic factors of physical and mental development and is known as motor skills. This term originates "from the Latin "movere" and represents" the set of processes and mechanisms throug which the human body or its segments move, detaching themselves from a landmark, by physical or dynamic muscle contractions, or maintain their posture by tonic contractions [1].
According to Brus, A., Hauspie, R., Panuel, M., \& Boëtsch, G. (2005) there is numerous researches carried out since the first decades of the 19th century which have shown that the level of physical development of children and adolescents is influenced by the living conditions of the population from which they come [2].

Cordeanu, A., et. al. (2008) states that the level of physical development as a quantitative expression of the biological potential of a community presents over time a dynamic strictly determined by

\footnotetext{
1 PhD, „Dunărea de Jos” University, Faculty of Physical Education and Sports, Galați, România

2 Department of Individual Sports and Kinetotherapy, University of „Dunărea de Jos”, România
} 
positive or negative oscillations in living standards, caused by periods of economic prosperity or economic crises, social calamities, such as periods of war or natural disasters, increasing the level of education and culture, or delaying access to culture [3].

Research on large sections of the population carried out since 1950 and repeated in 1957, 1964 and 1971, 1978, $1985,1992,1999$, showed that even in our country the staturo-weight development of children and adolescents is part of a process of acceleration and deceleration of physical development, reflected in the oscillations of the somatometric environment and in the somatomorphological changes of the prepubertal and pubertal period. To this end, studies have been carried out since 1950 and now on the main somatic indicators of physical development in a group of children and adolescents aged 0 to 18 years, respectively for the urban and rural population of the whole country [4].

Physical development, technical training and coordination skills are key factors in high athletic performance [4]. In some sports harmonious physical development is necessary, in others a specific physical development and in others physical development is of major importance only for maintaining a good state of health [5].

The evaluation of physical development is made on the basis of anamnesis: somatoscopic examination (global and segmentary), somatometric examination (measurement and calculation of anthropometric indices) as well as evaluation of the state of nutrition [6].

Vicious posture and weak muscles are common in children, and effective methods should be adopted to improve them in a sports training lesson, which requires the need to know the anatomicalphysiological features of growth and development of children and adolescents [7], [8], [9].

According to Dragan I. (2012) the method of sports training is in a continuous process of evolution, the mental and physical qualities of the athlete providing a solid basis in consolidating the technical and tactical elements [10]. In its view, training is a complex, multilateral, psychosocial, morphofunctional and methodologicalpedagogical process that aims to create an individual with a high level of sanogenesis, a higher degree of resistance to various environmental or endogenous factors, with a high capacity of effort and an adequate neurocortical and neuroendocrine-vegetative balance, all materialized in the possibility of achieving outstanding sporting performance[11].

The most important forms of motor stress are the motor qualities, which can be broken down into conditional qualities, coordination qualities (coordinating) [11], where speed, strength and endurance are basic motor skills [12] and agility together with coordination of the elements of the musculoskeletal system are components of psychomotricity [13].

USING ANTHROPOMETRIC MEASUREMENTS, ANALYZING THE BODY (BOUCHARD) OR NUTRITION INDEX (QUETELET), INVESTIGATING THE ABILITY TO ADAPT TO EFFORT AND THE DEGREE OF DEVELOPMENT OF PSYCHOMOTOR QUALITIES, WE CAN SEE HOW THE CADETS AND JUNIORS EVOLVE FROM YEAR TO YEAR AND FINALLY WE CAN OBSERVE THE DYNAMICS OF THEIR PHYSICAL AND MOTOR DEVELOPMENT.

\section{Materials and Methods}

The subjects of the research are 
represented by cadets and juniors of the Kazumi-Focşani Sports Club, students of grades IX-XII of the Ioan Slavici Theoretical High School, Panciu - Vrancea, in total of 116-boys (table No. 1 ).

Table 1 Number of subjects enrolled in research

\begin{tabular}{|l|l|l|l|l|}
\hline $\begin{array}{l}\text { Categories: } \\
\text { Cadets and } \\
\text { juniors }\end{array}$ & $\begin{array}{l}\text { l4- } \\
\text { year } \\
\text { old }\end{array}$ & $\begin{array}{l}\text { l5- } \\
\text { year } \\
\text { old }\end{array}$ & $\begin{array}{l}\text { l6- } \\
\text { year } \\
\text { old }\end{array}$ & $\begin{array}{l}\text { 17- } \\
\text { year } \\
\text { old }\end{array}$ \\
\hline $\begin{array}{l}\text { Number of } \\
\text { athletes }\end{array}$ & 29 & 29 & 29 & 29 \\
\hline Total & \multicolumn{4}{|c|}{116} \\
\hline Gender & \multicolumn{4}{|c|}{ Masculin } \\
\hline
\end{tabular}

The methods of scientific research are those of the whole process of training and education (pedagogical, psychopedagogical type), with some adaptations dictated by the specifics of our field. There are other areas (statistics) that offer us very useful methods in our field research.

In order to examine the content and complex of motor activity in training lessons, we have applied research methods, by which we plan to obtain concrete data on the level of force development and resistance to cadets and juniors.

As methods we used: the study of literature, pedagogical observation, experiment, evaluation tests and samples, mathematical calculation, analysis of results and graphic representation.

\subsection{Functional and motor assessment tools}

In carrying out scientific research we used the following means of work: metric tape, the scale, the timer.

Metric band (subdivisional measure of length, which represents a hundredth part of a meter) - narrow ribbon that can be of the cover, metal etc. long of one meter or more, with decimal divisions. We used this tool to perform anthropometric measurements (waist - height, abdominal perimeter in orthostatism, abdominal perimeter in dorsal decubit, thoracic perimeter at rest, thoracic perimeter in deep breath and deep exhale) [14].

The scale- tool for determining the weight of a body (determining the mass of a body), used to assess as accurately as possible the weight of the subjects involved in the study.

Timer- a special tool, which has specific functions, recording with great accuracy the time intervals. This tool has become indispensable in sports competitions and in setting records over a fixed period of time. We used this tool to record as well and accurately as possible for motor and functional samples.

For anthropometric measurements we used the following tests:

- height measurement, in centimeters (waist): this was performed with the thaliometer in the standing position, heels pressed together, the tips slightly apart, back straight against the wall, looking ahead, the cursor touches the vertex and records the height;

- weight measurement, in kilograms: performed in a light outfit, using the scale;

- chest perimeter

- the body mass (Bouchard) or nutrition index (Quetelet) - G/T - is calculated by dividing the weight into grams at the waist, in centimeters;

- $400 \mathrm{~g} /$ for each $\mathrm{cm}$ of body height medium body life/good nutrition status;

- up to $500 \mathrm{~g} /$ for every $\mathrm{cm}$ of body height - increased body life/increased nutrition status;

- more than $500 \mathrm{~g} /$ for each $\mathrm{cm}$ of body height - fattening trend; 
- up to $300 \mathrm{~g} /$ for every $\mathrm{cm}$ of body height - low body lets go;

- less than $300 \mathrm{~g} /$ for every $\mathrm{cm}$ of body height - unsatisfactory nutrition status.

For the evaluation of the ability to adapt to the effort we used the following tools/sample:

- The Ruffier test, a physical condition assessment test, which is based on variations in heart rate in three moments: rest; after effort; Return. The test consists of performing 30 squats, for 45 seconds and tracking the heart rate during the return period, lasting 1 minute:

a) the pupil in the sitting position, heart rate is measured at rest for 15 seconds; the value obtained shall be multiplied by 4 , the result shall be recorded in the corresponding column - P1;

b) heart rate is measured after exertion after 30 squats in 45 seconds; flexion in the hip and knee joint is performed up to 900;

c) the pupil in the seated position, in the last 15 seconds, the heart rate is measured again; the value obtained shall be multiplied by 4 , the result shall be recorded in the corresponding column - P2;

d) the pupil in the sitting position, the return heart rate is measured in the last 15 seconds of the first minute post-effort, the figure obtained is multiplied by 4 , the result is noted in the corresponding column - P3 [15].

The student must be equipped with ease. Calculate the Values of the Ruffier Index using the formula below and compare the reference values.

$$
\frac{(P 1+P 2+P 3)-200}{10}
$$

Note:

Very good : < 0;

Good: $\quad 0-5$;

Medium: $5-10$;

Satisfactory: $10-15$;

Unsatisfactory: > 15

To assess the degree of development of motor skills we used the following samples:

- $50 \mathrm{~m}$. flat speed run, starting from the bottom - athletes run in series of two, by colour, recording the time achieved by each competitor, from the moment of the sound signal until the end line is exceeded with the chest;

- resistance running, 1000 m boys - run on a measured and marked field; record the distance travel time, stops, route walking or abandoning appreciating with a grade 1 (one);

- push-ups - from the facial support position, on the palms and toes, bending the arms at an angle of less than 90 degrees (the chest reaches near the ground) and returning to the starting position; the number of correct executions is recorded;

- lifting the torso from the dorsal lying from the dorsal lying position with the knees bent, the soles on the ground with the tips held by a colleague and the palms at the back of the head raise the torso to the vertical, touching the knees with the elbows; the correct number of executions is recorded;

- extension of the trunk of the facial lying;

- from the facial lying position, with the palms to the back of the neck and the grip at the ankles - extensions of the torso, the chin exceeding the height of a gym bench located, as a landmark, in front of the performer and returning to 
the original position; the correct number of executions is recorded.

\section{Presentation of the Results of Scientific Research}

Table 2

Average results of anthropometric measurements in cadets and juniors - beginners

\begin{tabular}{|l|r|r|r|r|}
\hline $\begin{array}{c}\text { Average } \\
\text { arithmetic }\end{array}$ & Height & Weight & \multicolumn{1}{|c|}{$\begin{array}{c}\text { Thoracic } \\
\text { perimeter }\end{array}$} & $\begin{array}{c}\text { Corporate Mass } \\
\text { Index }\end{array}$ \\
\hline 14 -year old & 1,60 & 51,31 & 74,90 & 21,96 \\
\hline 15 -year old & 1,62 & 56,93 & 74,90 & 21,91 \\
\hline 16 -year old & 1,67 & 61,00 & 74,70 & 22,03 \\
\hline 17 -year old & 1,67 & 61,24 & 80,14 & \\
\hline
\end{tabular}

As can be seen from the centralizing table no. 2 and chart No. 1 the value of the average registers, during the high school period, increasing values at height by $7 \mathrm{~cm}$, by weight by $10 \mathrm{~kg}$, at the thoracic perimeter by $6.4 \mathrm{~cm}$ and at the body mass index by 2 units.

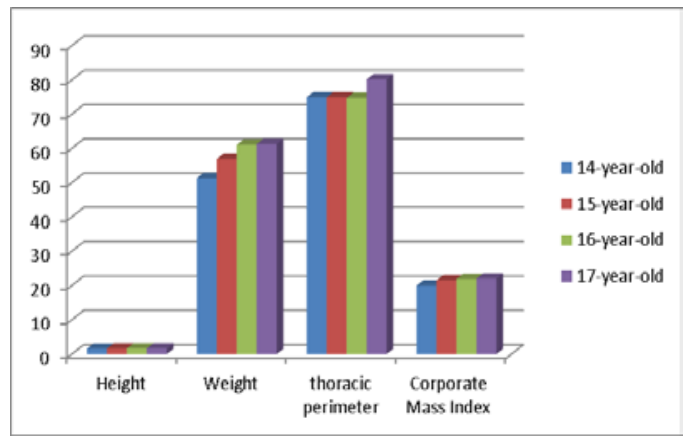

Fig. 1. Graphic representation of anthropometric measurements

\begin{tabular}{|l|c|c|c|c|}
\hline $\begin{array}{l}\text { Average } \\
\text { arithmetic }\end{array}$ & P1 & P2 & P3 & $\begin{array}{c}\text { Ruffier } \\
\text { Index }\end{array}$ \\
\hline 14-year old & 70,09 & 121,00 & 72,54 & 6,36 \\
\hline 15-year old & 68,26 & 124,91 & 75,13 & 6,83 \\
\hline 16-year old & 69,36 & 125,42 & 74,31 & 6,85 \\
\hline 17-year old & 67,52 & 124,85 & 71,42 & 6,38 \\
\hline
\end{tabular}

We see from Table No. 3 and chart No. 2 the value of the average in the Ruffier index does not, during the high school period, show improvements.

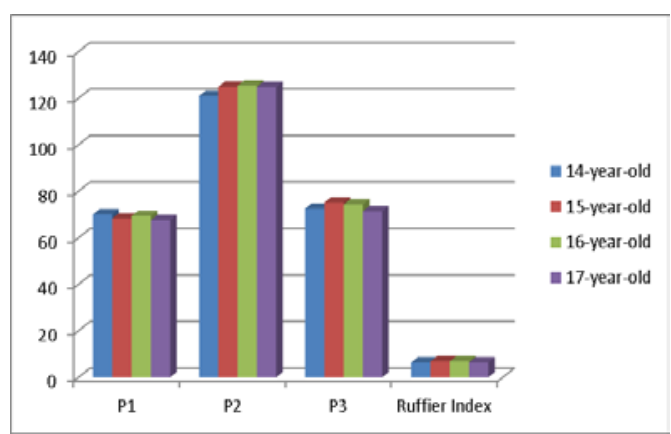

Fig. 2. Graphic representation of the Ruffier Index

Table 3

Average results of effort adaptation capacity for cadets and juniors beginners 
Average motor capacity results for cadets and juniors - beginners Table 4

\begin{tabular}{|l|r|r|r|r|r|}
\hline $\begin{array}{c}\text { Average } \\
\text { arithmetic }\end{array}$ & $\begin{array}{c}\text { Speed } \\
\text { running }\end{array}$ & $\begin{array}{c}\text { Resist. } \\
\text { running }\end{array}$ & \multicolumn{1}{c|}{ Floats } & \multicolumn{1}{c|}{ Crunches } & Back \\
\hline 14 -year old & 7,33 & 4,44 & 15,10 & 25,03 & 18,21 \\
\hline 15 -year old & 7,22 & 4,23 & 17,00 & 26,00 & 21,66 \\
\hline 16 -year old & 7,20 & 3,18 & 18,70 & 27,83 & 25,91 \\
\hline 17 -year old & 6,83 & 3,28 & 20,55 & 27,83 & 27,83 \\
\hline
\end{tabular}

From table No. 4 and chart No. 3 We note that the value of the average during the high school period, records, improvements to the motor capacity assessment samples : in running speed on $50 \mathrm{~m}$ flat, with a bottom start of 0.50 seconds, at running $1000 \mathrm{~m}$ boys with 1.16 minutes, push-ups with 5.45 repetitions, lifting the trunk from the dorsal bed with 20 repetitions and extension of the trunk from lying down with 12.41 repetitions.

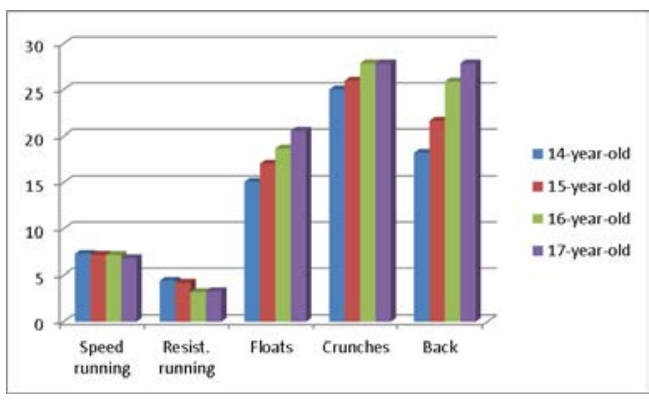

Fig. 3. Graphic representation of the average values of motor capacity

\section{Conclusions}

Following this research we have come to the following conclusions:

- whereas during the high school period the value of the average registers the height-raising, thoracic perimeter and body mass index, we see a positive dynamic in anthropometric development, which validates the first working hypothesis that the pace of physical development of the cadets and juniors is different from one year to another;

- the average value of the Ruffier index does not register during the high school period improvements, aspect determined by the small number of hours of physical education, which disproves the first part of the hypothesis that the capacity to adapt to effort, to the cadets and juniors is continuously improved but confirms the part of the hypothesis that the capacity to adapt to effort is different from one year of study to another;

- during the high school period, the value of the average, records, improvements to the motor capacity assessment samples and we can support the validation of the hypothesis that the rate of motor development of the candidates and juniors is different from one year to the next;

- in the course of training and physical development, it must be assumed that no individual is physically identical to another, each is different from the others in relation to age, level of sporting experience and his physical and mental qualities;

- the process of developing motor skills gives us wide and concrete possibilities for objective assessment of the progress made by athletes; from this perspective, the objectification of the process of development of motor qualities requires the coach to know the level of training of the athletes, in order to know from which stage it starts. 


\section{Acknowledgments}

This work was supported by the project ANTREPRENORDOC, in the framework of Human Researches Development Operational Programme 2014-2020, financed from the European Social Fund under the contract number 36355/23.05.2019 - cod SIMS: 123847.

\section{References}

1. Adam, A. M., Simion, G., Iconomescu, T.: Psychomotor Capacities In The Dancesport Training. In: The impact of Sport and Physical Education Science on Today's Society, 11, 2018.

2. Belomazheva-Dimitrova, S.: Changes in some performance indicators folowing the implementation of an experimental model for body corpus muscle stability in physical education and sports classes. In: Trakia Journal of Sciences, 2020, 18(1), p. 741-747.

3. Brus, A., Hauspie, R., Panuel, M., Boëtsch, G.: Analyze of the same-time parents (Limousin, France). Groupement des Anthropologies de Langue Française, Toulouse, Communication, 2005.

4. Cordeanu, A., Bucalet, C., Stănescu, C., Dumitrache, C., Nicolescu, R., Elena Nastase, , Kassai V. , losif I. , Pîrvu S., Stoian Pantea A.., Stoian Pantea, A.: Dynamics of physical development of children and adolescents in Romania in the last 50 years. In: Journal of Hygiene and Public Health, 2008, 58(2), p. 97-106.

5. Dobre, A. G.: Study on the impact of the Analysis of the kinetic parameters of the middle-distance runner step in the improvement of the junior technique. In: Bulletin of the Transylvania University of Brasov. Series IX, Sciences of Human Kinetics, 2020, 13(1), p. 37-46.

6. Dobre, A. G., Mereuţă, C., Grigore, F. E.: The importance of technical analysis for improving performance in athletics in long distance running. In: Annals of the University Dunarea de Jos of Galati: Fascicle XV: Physical Education \& Sport Management, 2019, (2).

7. Dragnea, A., Bota, A., Stănescu, M., Teodorescu, S., Sherbanoiu, S., Tudor, V.: Physical education and sport. Theory and teaching. FEST Publishing. Bucharest, 2006.

8. Dudnic, E., Dudnic, N.: Particularitățile dezvoltării calităților motrice ale copiilor și juniorilor (Special fetarures of the development of the motive qualities of children). In: Integrare prin cercetare și inovare, 2019, p. 19-22.

9. Ifrim, M.: Motor Anthropology. Bucharest, Scientific and Encyclopedic Publishing House, 1986, p.18.

10. Mocanu, G. D., Mocanu, M. D., lordan, D.A.: Research Regarding Sending Free Time of Students Participating In the Physical Education-Professional Conversion Program. In: GYMNASIUM, 2020, 21(2), 25-50.

11. Nikolakakis, A., Mavdidis, G. Gourgoulis, V., Pilianidis, T., Rokka, S.: Effect of an intervention program that use elastic bands on the improvement of the forehand topspin stroke in young table tennis athletes. In: Journal of Physical Education and Sport, 2020, 20, p. 2189-2195. 
12. Postelnicu, M.G., Mihaila, I.: 14. https://dexonline.ro/text/metru\%20m Correlations between the Coordinating Capacities and the Technical Parameters at the Level of the Handball Teams (Junior III). In: Lumen Proceedings, 12, 2020, p.309-315.

13. https://www.pansportmedical.ro/dez voltare/articole/despre_dezvoltarea_f izica.html.

15. Silisteanu, S. C., Silisteanu, A. E. (n.d.) Studiu privind evaluarea capacităţii de efort la studenţii universităţii ,, Ştefan cel Mare" Suceava (Study on the asessement of the effort capacity of students at the "Ştefan cel Mare" Univeristy). Available on: http://bioclima.ro/75CNB.pdf. 